\title{
Effect of the angles of the cracks of corroded plate in bonded composite repair
}

\author{
Salem Mokadem, Berrahou Mohamed, Mechab Belaïd, Belabbes Bachir Bouadjra \\ University of Djillali Liabes, LPMM Laboratory, Sidi Bel Abbes, Algeria \\ moka_salem@yahoo.fr,berrahou22@yahoo.com,bmechab@yahoo.fr,bacbirbou@yahoo.fr
}

\begin{abstract}
In this study a three-dimensional finite element method analysis of repairing plate with bonded composite patch subjected to tensile load was presented. The effect of the corrosion on the damage of the adhesive (FM73) in the length of inclined crack is presented. The obtained results show that the increase of $\left(\mathrm{D}_{\mathrm{R}}\right)$ is due to the increase of the inclination of the crack against it leads to the decrease of the values of the stress intensity factor in mode I $\left(K_{I}\right)$.
\end{abstract}

KEYwords. Composite repair; Corrosion; Damage ratio; Finite element method (FEM); Stress intensity factor in mode I and mode II $\left(K_{I}, K_{I I}\right)$.

\section{OPEN ACCESS}

Citation: Salem, M., Berrahou, M., Mechab, B., Bachir Bouadjra, B., Effect of the angles of the cracks of corroded plate in bonded composite repair, Frattura ed Integrità Strutturale, 46 (2018) 113-123.

Received: 23.05 .2018

Accepted: 18.06 .2018

Published: 01.10.2018

Copyright: (C) 2018 This is an open access article under the terms of the CC-BY 4.0, which permits unrestricted use, distribution, and reproduction in any medium, provided the original author and source are credited.

\section{INTRODUCTION}

$\mathrm{B}$ onded composite repairs of metallic structure have become a useful aircraft structural life extension solution over the last two decades. These repairs provide an efficient method for restoring the ultimate load capability of the structure [1]. Alan Baker [2,3] was the first otherwise the pioneer of these searches in the aeronautical and maritime research laboratory of the Royal Australian Air Force.

The first published study on the corrosion of composite metal matrix (CMM) materials was probably that of Porter and Wolff in 1967. Current CMM corrosion resistance publications focus on matrix materials for the most part of aluminum reinforced with carbon or silicon carbide, with fibrous or particulate form.

Composite materials with aluminum matrix reinforced with carbon fibers $(\mathrm{C} / \mathrm{Al})$ are the subject of this publication work. Composite materials $(\mathrm{C} / \mathrm{Al})$ clearly show very low resistance to corrosion in chloride media, whether in marine atmosphere, salt spray or immersion in seawater [4].

The various journals, gathering the results obtained on this topic before (1997), distinguish two main forms of corrosion in these materials: the hydrolysis of aluminum carbides (A14C3) and the galvanic corrosion between carbon and aluminum $[5,6]$.Corrosion of composite materials $(\mathrm{C} / \mathrm{Al})$ is a topic that cannot be addressed without studying the influence of alloy reinforcement on corrosion resistance. The vast majority of authors are interested in the chemical nature of the 
reinforcements (silicon carbide, carbon, alumina, boron), but few of them have studied their volume fraction in the material, their morphology and the fiber / matrix interfaces.

Recently, some studies have taken into account the effect of corrosion on composite patch repair. Berrahou and Bachir Bouiadjra [7] analysed the damage of the adhesive for different forms of patch in the repair of aluminum plates by composites, The obtained results show that the adhesive damage localized at the level of corrosion and in the sides of the patch, and the rectangular patch offers high safety it reduces considerably the risk of the adhesive failure.

In another study, Berrahou et al [8] studied the effect of the corrosion of plate with double cracks in bonds composite repair the obtained results show that the crack on the left side creates a very extensive area of the damaged zone and gives values of the stress intensity factor (SIF) higher than that on the right side. We can conclude that the left crack is more harmful (dangerous) than that on the right side.

The protection of aluminum alloys against marine corrosion is a topic that has been widely studied to date. The books dedicated to this subject are numerous and exhaustive [9]. The usual techniques used to protect aluminum have been tested on composite materials $(\mathrm{C} / \mathrm{Al})$.

About the effect of the patch form, Bachir Bouiadjra et al [10] compared the two rectangular and trapezoidal patch forms. They showed that the trapezoidal shape improves the efficiency and durability of repair.

The finite element method has been used for the study of the crack patching by many authors, we can quote: Many researchers have studied crack reinforcement of stiffeners or pre-stresses on the stress intensity factor at the cracks tip or notches by the optical method of caustics [11-13].

The damaged area criterion has been proposed to analyse the damage in the adhesive [14,15]. This criterion assumes that the material breaks once the measured stress exceeds the ultimate strength of the material. Damage in the adhesive layer occurs when the deformations or stresses in the adhesive are locally larger than the ultimate properties of the materials. The break in the adhesive does not occur by the propagation of cracks in the substrate, but rather by the initiation and propagation of the damaged area in the layer containing defects such as micro-cracks or voids [16]. The surface area of the adhesive is defined by a surface, where the deformations of the maximum permissible deformation and the breaking load of the glue joints have been determined experimentally. This model has been widely used in the literature to predict the detachment of the adhesive. Chang-Su Ban et al [17] introduced modifications on the model of the damage zone of Sheppard et al [15].

The ratio of the damaged area has been suggested for the prediction of the breaking load of the glue joint. For the epoxy adhesive (FM 73), it has been shown that the ratio of the damaged area corresponding to the failure of this adhesive is 0.247. Apalak et al [18] used the damaged zone theory to analysis of the effects of thermal stresses in the glue joint. They showed that damage can be expected in composites as well as in the adhesive when using soaked adhesives.

Recently, several papers describing the damage zone theory published. We note the work of $[7,8]$ which work on the effect of the corrosion on the damage of the adhesive (FM73) on the repair efficiency and we noted also that [19] has estimated the adhesive damage and failure in the bonds composite repair of aircraft structures using modified damage zone theory. Benyahia et al. and Ramji et al. [20,21] analysed four different shapes (rectangular, trapezoidal, circular and elliptical). Benyahia and Fari Bouanani [22] evaluated the effect of water absorption on the adhesive damage in the bonds composite repair of aircraft structures.

In this study, a three-dimensional finite element method is used to analyse the effect of the corrosion on the damage of the FM73 epoxy adhesive of bonded composite repair of aircraft structures. After variation of the crack inclination $\theta=$ (15-30-45-60-75) $)^{\circ}$, and determination of different graphs of the ratio of the damaged zone and the curves of variation of stress intensity factor, one proceeds to the comparison between the different forms of the patch to determine the effect of the angle of the crack.

\section{GEOMETRICAL AND FE MODELS}

$\mathrm{F}$ or the study of the repaired mode II crack behaviour, we consider an aluminum plate (Al 2024-T3) having the following dimensions: $\mathrm{H}_{\mathrm{pl}}=254 \mathrm{~mm}, \mathrm{~W}_{\mathrm{pl}}=254 \mathrm{~mm}$ and $\mathrm{e}_{\mathrm{pl}}=5 \mathrm{~mm}$, with a crack inclined at an angle $\theta$.

The plate is subjected to uniaxial load $\sigma=100 \mathrm{MPa}$ presented in Fig. 1. The crack is repaired with a patch boron / epoxy, the thickness $e_{\mathrm{pa}}=1.5 \mathrm{~mm}$ and the adhesive (FM-73) properties $\mathrm{G}_{\mathrm{pa}}=0.420 \mathrm{GPa}$ and the thickness of adhesive it's $e_{a d}=0.15 \mathrm{~mm}$. The mechanical properties of the patch plate and of the adhesive are shown in Tab. 1. The geometric shape of the corrosion used is randomly in $3 \mathrm{D}$ with a thickness $0.25 \mathrm{~mm}$, before repairing the structure, the corroded area is cleaned to remove the Corrosion film and keep the same mechanical properties. 
The considered plate was subjected to uniaxial tensile load in the vertical direction under a stress $\sigma=100 M P a$. The commercial finite elements code ABAQUS V.6.11 was used for computation Abaqus [23]. The mesh model contains 47150 linear hexahedral elements of type C3D8R and 35965 quadratic tetrahedral elements of type C3D10 (8 nodes biquadratic plane stress with reduced integration) with a grid refined and structured in the vicinity of the notch as shown in Fig. 1. Total number of nodes 124248. In the presence of principal crack, the number of the quadrilateral elements of type CPS3 (3 nodes linear plane stress triangle). Plane stress conditions were assumed.

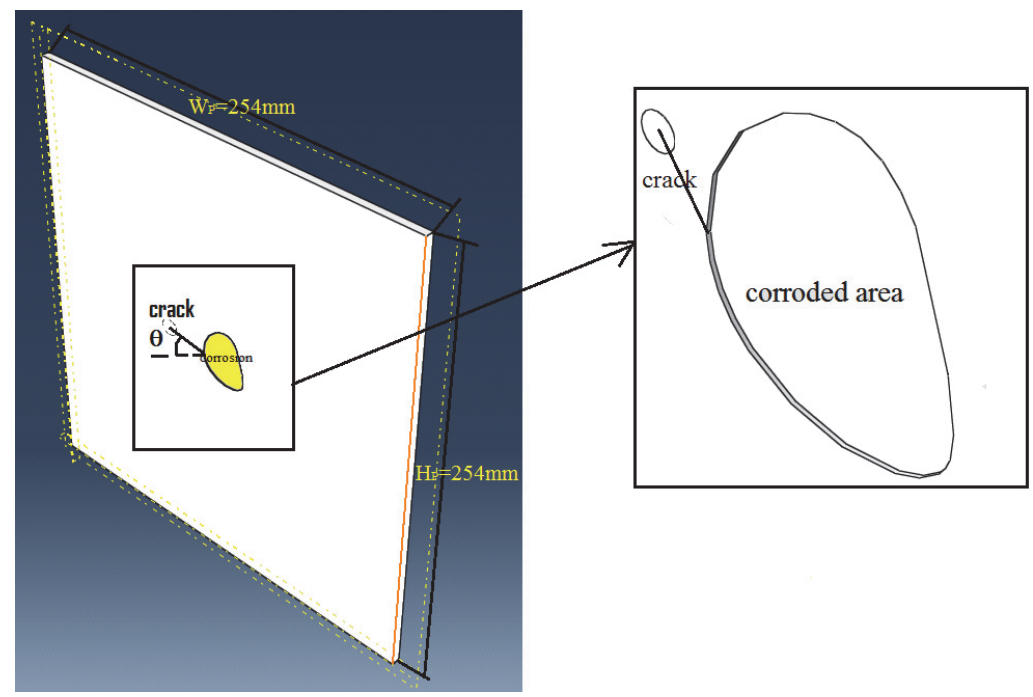

Figure 1: Geometrical model.

The singularity at the crack tip by special quarter-point elements [24]. The parameters of crack, $K_{I}$ and $K_{I I}$ are given by the stresses at the crack tip. At the crack tip 160 quadrilateral linear elements were considered Fig. 1. However, to generate crack front some brick elements are replaced by "crack-blocks". These crack-blocks are meshes of brick elements, which are mapped into the original element space and merged with surrounding mesh. The mesh was refined near the crack tip area with an element dimension of $0.05 \mathrm{~mm}$ using at least fifteen such fine elements in the front and back of the crack front. Fig. 2 shows the total mesh of the corroded plate and the mesh for different forms of glue. The stress intensity factor (SIF) at the crack front was extracted using the virtual crack closure technique (VCCT).

The crack tip stress intensity factors are calculated using the Virtual Crack Closure Technique (VCCT) on the basis of the energy balance. In this technique, the stress intensity factors are obtained for the three failure modes according to the equation:

$$
G_{T}=G_{I}+G_{I I}+G_{I I I}
$$

and

$$
G_{i}=\frac{K_{i}^{2}}{E}
$$

where $G_{i}$ is the rate of energy restitution for mode $i, K_{i}$ is the stress intensity factor for mode $i$, II, III) and E is the modulus of elasticity.

\section{RESULTS AND DISCUSSION}

I $\mathrm{n}$ theory, it is stipulated that after the development of a damaged area there is an appearance of crack initiation in the patch glued with an adhesive. By applying a low intensity charge the damage is observed at the edges of the patch. This damage occurs because the material is subjected locally to deformations higher than the deformation. Under average load, damaged areas grow in size and the concentration of points in damaged areas increases. Because the breaking load is reached, the damaged area within the adhesive gets a critical size and with the merging of the individual 
components a crack is formed. Numerically, the damaged zone can be identified by the marking of the elements for which a criterion of rupture is exceeded. The analysed adhesive is a ductile adhesive. Therefore, the failure criterion used for cohesion damage of the adhesive layer is equivalent to the Von Mises deformation criterion.

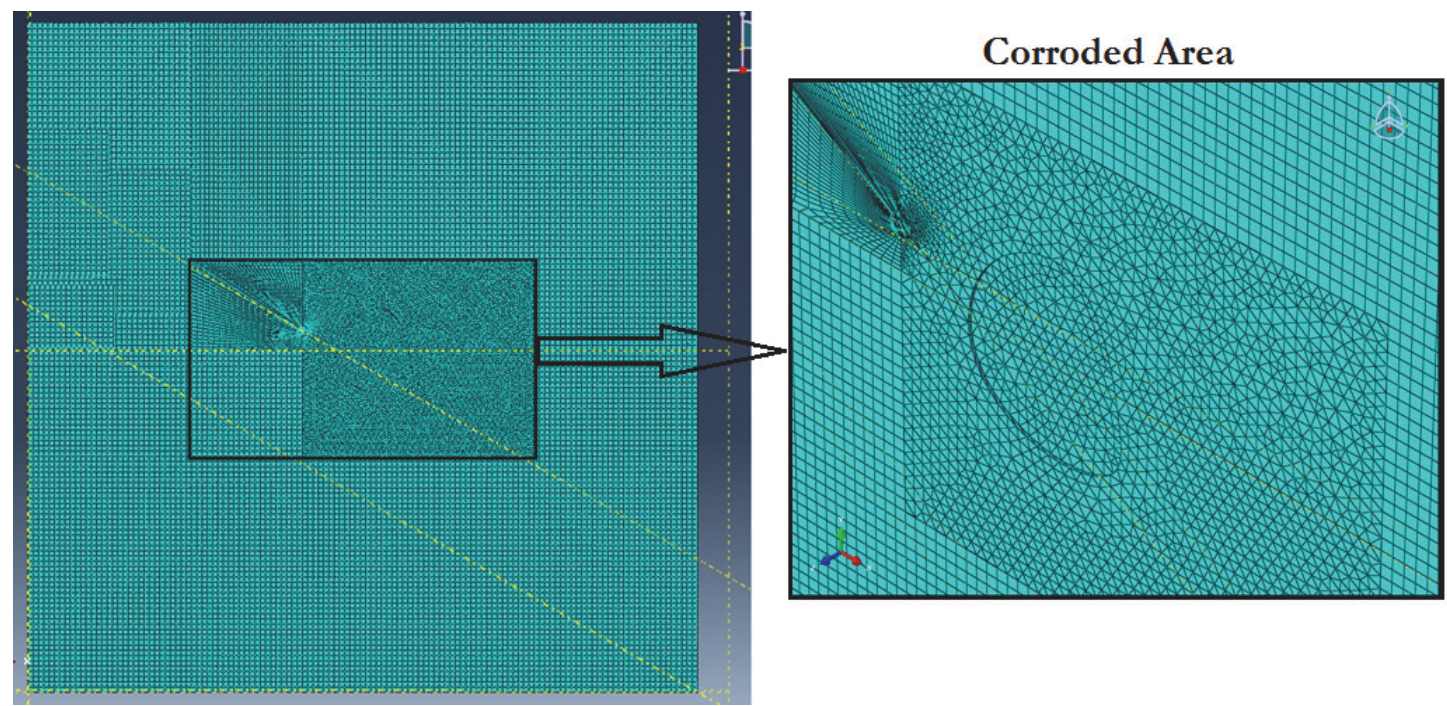

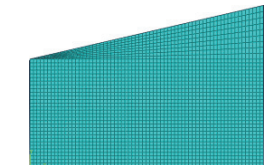

Trapezoïdal adhesive

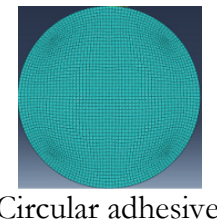

(a)



(b)

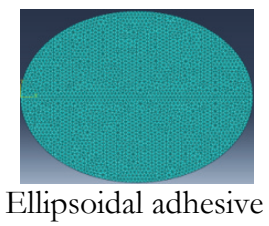

Figure 2: (a) Mesh of the corroded plate, (b) Mesh for different shapes of glue.

\begin{tabular}{|c|c|c|c|c|}
\hline Property & $\begin{array}{l}\text { Aluminum } \\
\text { (Al T2024) }\end{array}$ & $\begin{array}{l}\text { Material } \\
\text { Boron/Epoxy }\end{array}$ & $\begin{array}{c}\text { Adhesive } \\
\text { FM } 73\end{array}$ & Description \\
\hline $\mathrm{E}_{1}$ & 72 & 200 & 4.2 & Young's modulus in $\mathrm{X}$ direction (GPa) \\
\hline $\mathrm{E}_{2}$ & & 19.6 & & Young's modulus in Y direction (GPa) \\
\hline $\mathrm{E}_{3}$ & & 19.6 & & Young's modulus in $\mathrm{Z}$ direction (GPa) \\
\hline$\nu_{12}$ & 0.33 & 0.3 & 0.32 & Poisson's Ratio in X-Y plan \\
\hline$\nu_{13}$ & & 0.28 & & Poisson's Ratio in X-Z plan \\
\hline$\nu_{23}$ & & 0.28 & & Poisson's Ratio in Y-Z plan \\
\hline $\mathrm{G}_{12}$ & & 7.2 & & Shear modulus in $\mathrm{X}-\mathrm{Y}$ plan $(\mathrm{GPa})$ \\
\hline $\mathrm{G}_{13}$ & & 5.5 & & Shear modulus in $\mathrm{X}-\mathrm{Z}$ plan $(\mathrm{GPa})$ \\
\hline $\mathrm{G}_{23}$ & & 5.5 & & Shear modulus in Y-Z plan $(\mathrm{GPa})$ \\
\hline
\end{tabular}

Table 1: Mechanical proprieties of materials. 


$$
\varepsilon_{\text {equi }}=\frac{1}{\sqrt{2(1+v)}} X \sqrt{\left(\varepsilon_{p 1}-\varepsilon_{p 2}\right)^{2}+\left(\varepsilon_{p 2}-\varepsilon_{p 3}\right)^{2}+\left(\varepsilon_{p 3}-\varepsilon_{p 2}\right)^{2}}
$$

With $\varepsilon_{\text {equi }}$ it's the equivalent deformation, $\varepsilon_{p i}$ are the plastic deformations in the different directions and $v$ the Poisson's ratio. For the epoxy adhesive (FM 73), the damaged area is defined as a domain in which the deformation exceeds the ultimate deformation of $7.87 \%$ Chang-Su Ban et al [17] see Fig. 3. The adhesive failure criterion for the damaged area should be used. For isotropic materials, fracture criteria such as Von-Mises and Tresca can be used to better understand the take-off of the adhesive. In addition, the detachment of the joints can be predicted using the damaged area ratio method defined as follows.

$$
D_{\mathrm{R}}=\frac{\sum A_{i}}{l . w}
$$

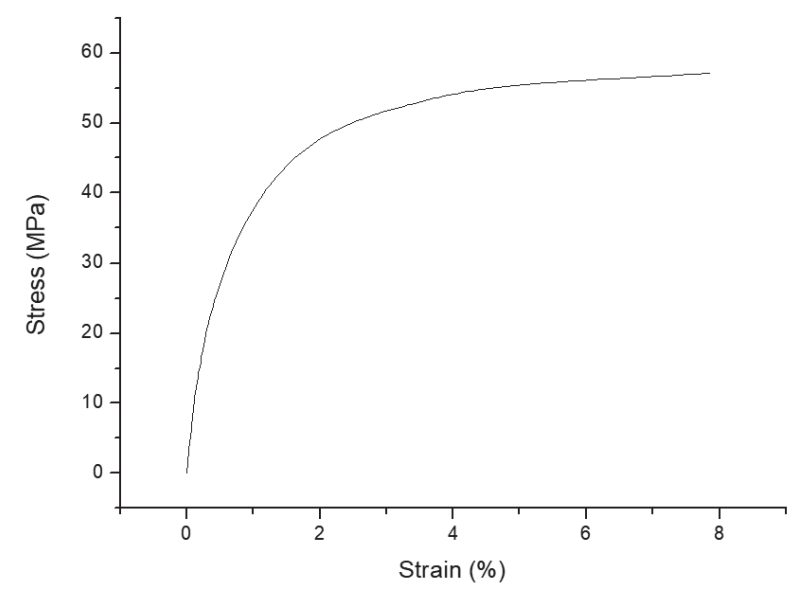

Figure 3: Stress-strain curve of FM 73 epoxy adhesive.

\section{Effect of crack inclination on the variation of the ratio of the damaged area of the adhesive}

The effect of the inclination of the crack is shown in Figs. (4, 6, 8 and 10). These show the variations of the damaged area of the adhesive as a function of the slope of the $\operatorname{crack}(\theta)$ for a constant length $(\mathrm{a}=30 \mathrm{~mm})$ repaired by simple patch.

The thickness of the adhesive $e_{a d}=0.15(\mathrm{~mm})$ and the thickness of the patch $e_{\mathrm{pa}}=1.5 \mathrm{~mm}$ was fixed for different patch shapes (rectangle, trapezium, circle and ellipse) and for an applied load equal to $100 \mathrm{MPa}$, firstly, then the crack inclinations $\theta=(15-30-45-60-75)^{\circ}$ were varied, after the determination of different ratio graphs of the damaged zone and the factor variation curves. The intensity of constraints one can make a comparison between the different forms of the patch to determine the effect of the crack inclination.

\section{Rectangular patch}

Fig. 4 shows the evolution of the damaged area according to the slope of the crack. In general, we find that the more the crack inclination increases more than the area of the damaged area increases. In the case of $\theta=15^{\circ}$ we note the presence of a very small damaged area surrounding the crack and the periphery of the patch. Comparing the obtained results for the inclinations $\theta=45^{\circ}$ and $\theta=75^{\circ}$ to those of $\theta=15^{\circ}$, we notice an increase in the size of the progressively damaged zone and a slight increase in the area around the periphery of the patch.

Fig. 5 highlights the ratio of the damaged area as a function of crack inclination. A steep slope is observed at the beginning of the graph, which explains the rapid increase. Then, it slows down gradually to $35 \%$, which is equivalent to a $4 \%$ decrease in the damaged area. For comparison between the values observed for the inclinations of $(\theta)$ ranging from $15^{\circ}$ to $30^{\circ}$ on the one hand and from $40^{\circ}$ to $75^{\circ}$ on the other hand. For the first case we have $\left(\mathrm{D}_{\mathrm{R}}\right)$ which varies from 0.23 to 0.241 , The increase is large and very fast, as for the second case the variation of the ratio of the damaged zone is not significant because the $\left(\mathrm{D}_{\mathrm{R}}\right)$ varies from 0.2415 to 0.242 . The obtained results in this study are always lower than the critical value $\left(\mathrm{D}_{\mathrm{RC}}\right)$ and this whatever the value of the inclination of the crack. 


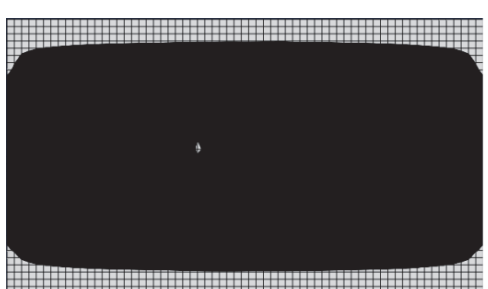

(a)

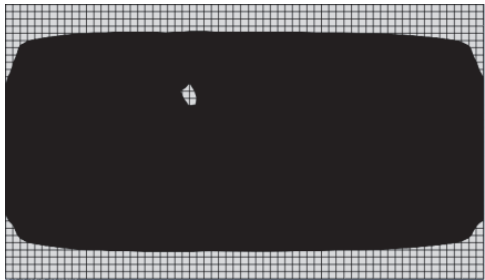

(b)

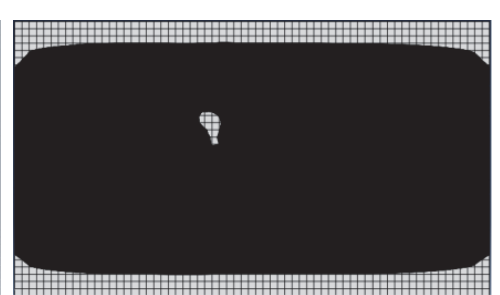

(c)

Figure 4: Damaged zone for a rectangular patch (a) $\theta=15^{\circ}$, (b) $\theta=45^{\circ}$ and (c) $\theta=75^{\circ}$.

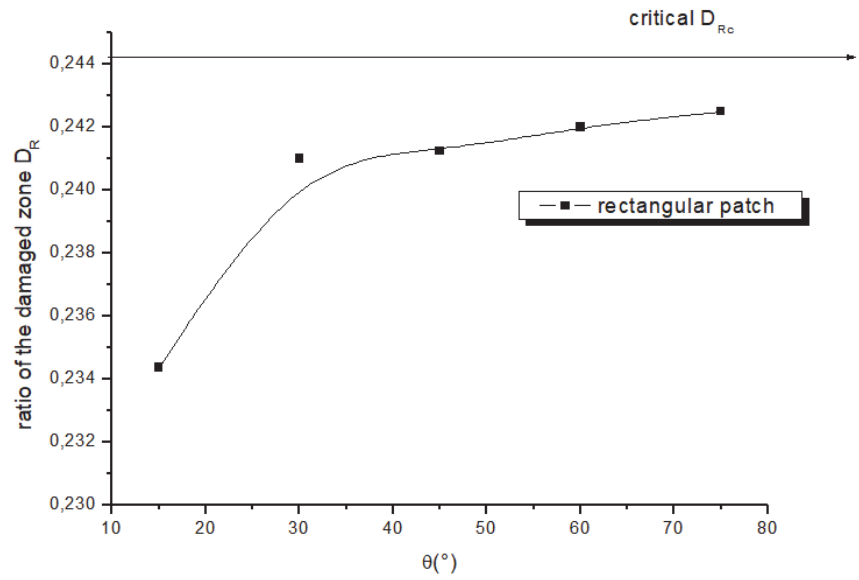

Figure 5: Ratio of the damaged area as a function of the crack tilt.

\section{Traperoidal patch}

The problem is to know the extent of the damaged area of adhesive as it was done before. Fig. 6 notes that we have the same behavior observed in Fig. 4. We note proportionality between the inclination of the crack and the damaged area. Comparing the cases of Fig. 6.a and 6.c it is clear the increase of the damaged area (shown in gray) as well as a slight increase of the damaged area at the edges of the patch.

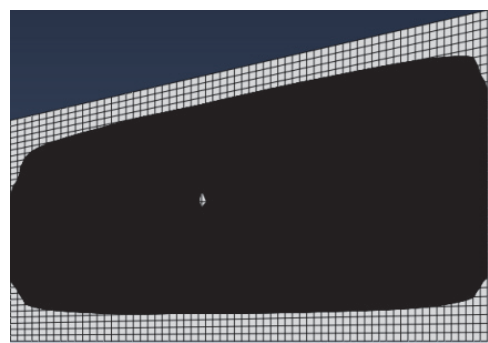

(a)

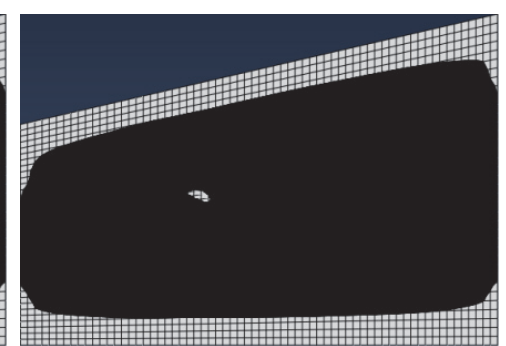

(b)

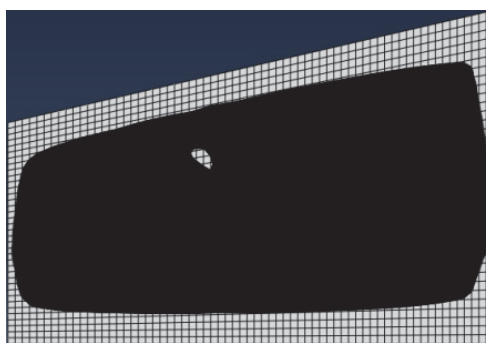

c)

Figure 6: Damaged zone for a trapezoidal patch (a) $\theta=15^{\circ}$, (b) $\theta=45^{\circ}$ and (c) $\theta=75^{\circ}$.

As it was observed previously in the case of Fig. 5, the $\left(D_{R}\right)$ increases with the increase of the inclination of the crack. Fig. 7 shows the variation of the ratio of the damaged area as a function of crack inclination. We observe two distinct parts of the first curve between $\theta=15^{\circ}$ and $\theta=30^{\circ}$ where the slope is small and therefore a small variation of the $D_{R}(0.25-0.27)$. In the second part of the curve between $\theta=30^{\circ}$ and $\theta=75^{\circ}$ we note that the slope is significant and constant the values of $\mathrm{D}_{\mathrm{R}}(0.27-0.42)$. All values of $\left(\mathrm{D}_{\mathrm{R}}\right)$ obtained are greater than that of $\mathrm{D}_{\mathrm{RC}}$ for all angles of inclination.

\section{Circularpatch}

Fig. 8 shows the variation of the damaged area using a circular patch. The findings made previously are very clearly visible here. Increasing the crack tilt directly leads to an increase in the size of the damaged area. The increase in the damaged area at the periphery of the patch is very visible compared to rectangular and trapezoidal shapes. 


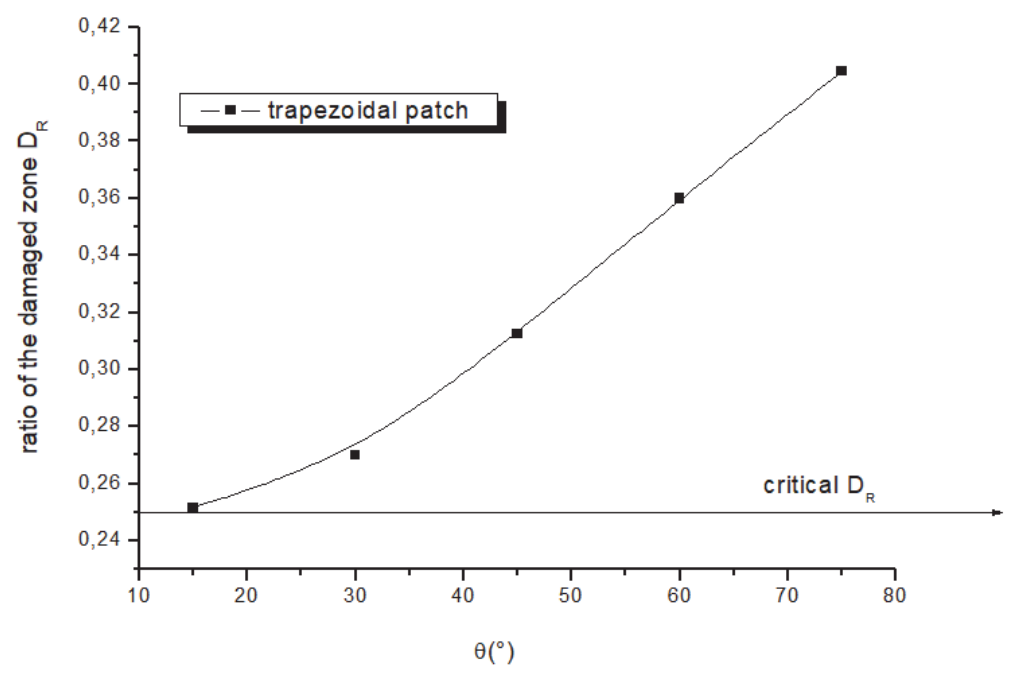

Figure 7: Ratio of the damaged zone according to the crack tilt.



(a)

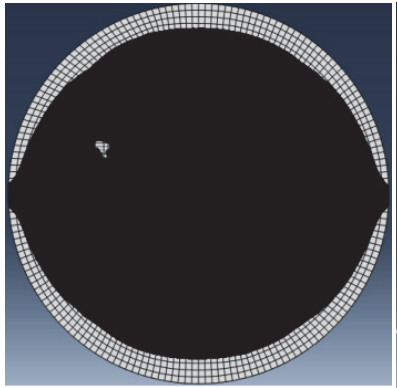

(b)

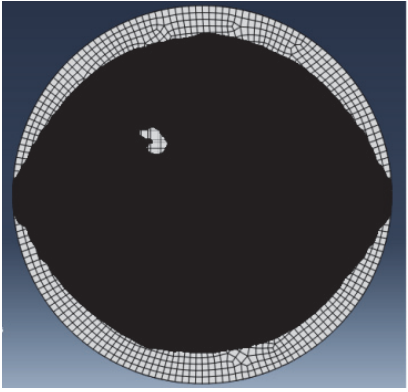

(c)

Figure 8: Damaged zone for a circular patch (a) $\theta=15^{\circ}$, (b) $\theta=45^{\circ}$ and (c) $\theta=75^{\circ}$.

The Fig. 9 shows the variation of the ratio of the damaged zone as a function of the inclination. Whatever the value of the inclination of the crack, it is noted that the critical value $\mathrm{D}_{\mathrm{RC}}$ has not been reached, and that the increase in the crack inclination directly leads to the increase of $\mathrm{D}_{\mathrm{R}}$.

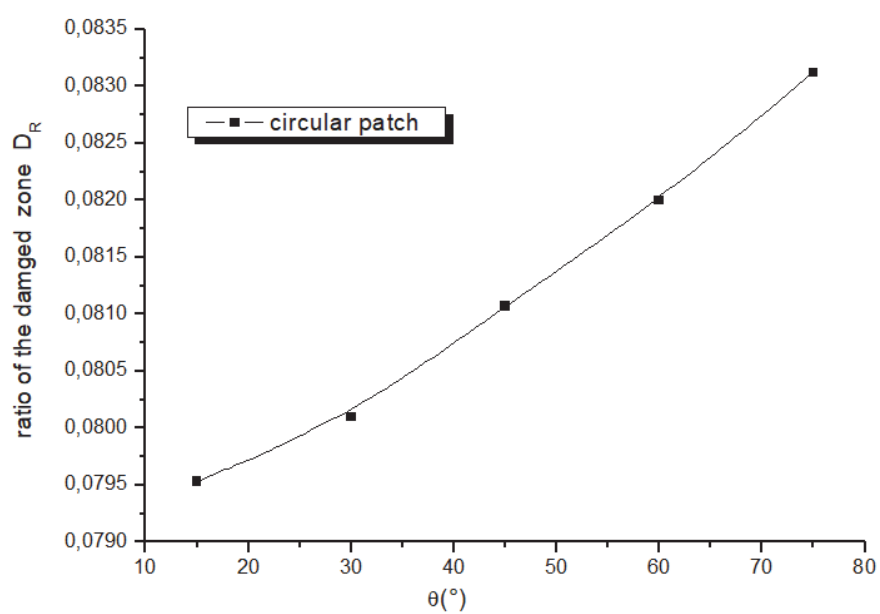

Figure 9: Ratio of the damaged zone according to the crack tilt. 


\section{Elliptical patch}

Fig. 10 illustrates the distribution of the damaged area of the adhesive for the following inclinations $\left(\theta=15^{\circ}, \theta=45^{\circ}\right.$ and $\theta=75^{\circ}$ ). By comparing the results found previously for patches of shapes (rectangular, trapezoidal and circular) to those of the elliptical we notice the appearance of the damaged area at the level of corrosion. This zone is visibly clear for $\theta=$ $75^{\circ}$ that $\theta=45^{\circ}$.

Same remarks as the previous cases, an increase in the inclination of the crack causes the increase of the damaged area surrounding crack as well as the area of the patch device.

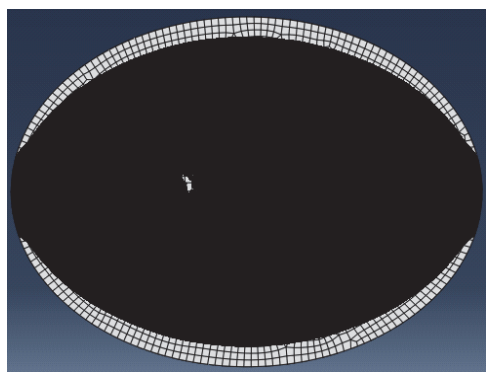

(a)

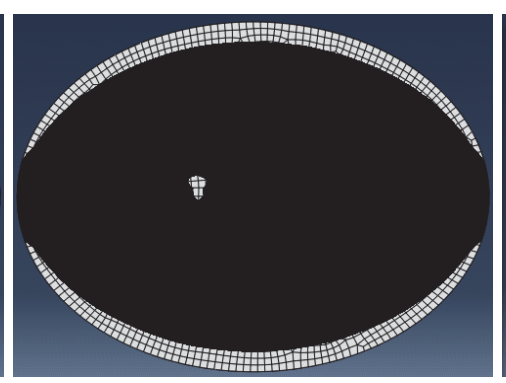

(b)

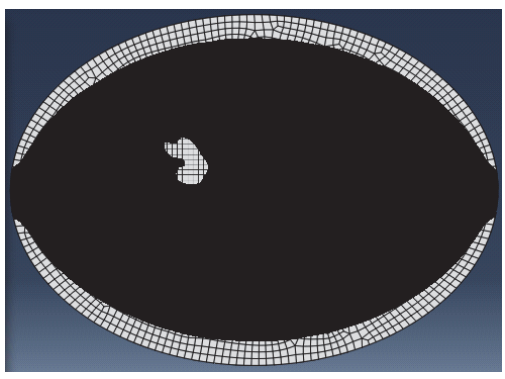

(c)

Figure 10: Damaged zone for a circular patch (a) $\theta=15^{\circ}$, (b) $\theta=45^{\circ}$ and (c) $\theta=75^{\circ}$.

Curve 11 represents the values of the ratio of the damaged area of the adhesive which increase progressively with increasing crack inclination. Starting from the value of $D_{R}=0.0795$ for $\theta=15^{\circ}$ until reaching the maximum value of $D_{R}=0.083$ for $\theta=75^{\circ}$. Note the critical value of the ratio $\left(D_{R C}=0.247\right)$ is not reached.

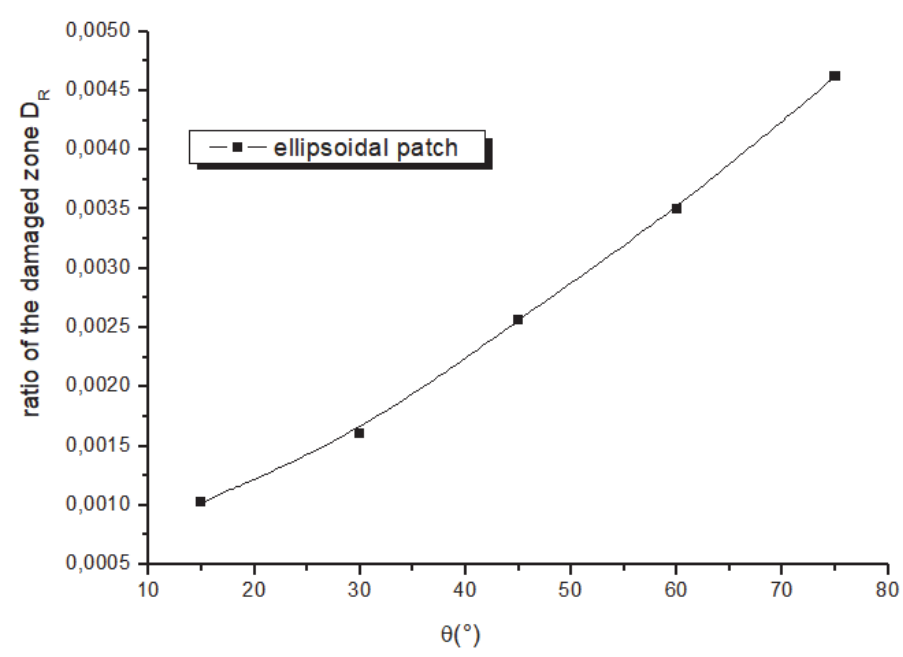

Figure 11: Ratio of the damaged zone according to the crack tilt.

Comparison between the different $\left(D_{R}\right)$ according to the inclination of the crack for the different forms of patch

In order to see the effect of the ratio of the damaged area for different inclinations of the crack the graph of Fig. 12 is analysed. It is noted that the increase of the crack inclination leads to an increase of $\left(D_{R}\right)$ for all the different forms of patch used. The $\mathrm{D}_{\mathrm{R}}$ recorded for the trapezoidal shape is greater than the critical value which is a risk of detachment of the patch from which this form is to be avoided for repair. On the other hand all the other forms give values of $D_{R}$ lower than the critical value $\left(\mathrm{D}_{\mathrm{RC}}=0.247\right)$. Among the results obtained the elliptical form is the best because it gives the minimum value of $\mathrm{D}_{\mathrm{R}}$.

\section{Effect of the inclination of the crack on the variation of the SIF}

The Figs. 13 and 14 respectively represent the variations of the SIF in mode I and II as a function of the inclination of the crack for respective thicknesses of the adhesive and of patch $\mathrm{e}_{\mathrm{ad}}=0.15 \mathrm{~mm}, \mathrm{e}_{\mathrm{pa}}=1.5 \mathrm{~mm}$ and a crack size $\mathrm{a}=30 \mathrm{~mm}$. 


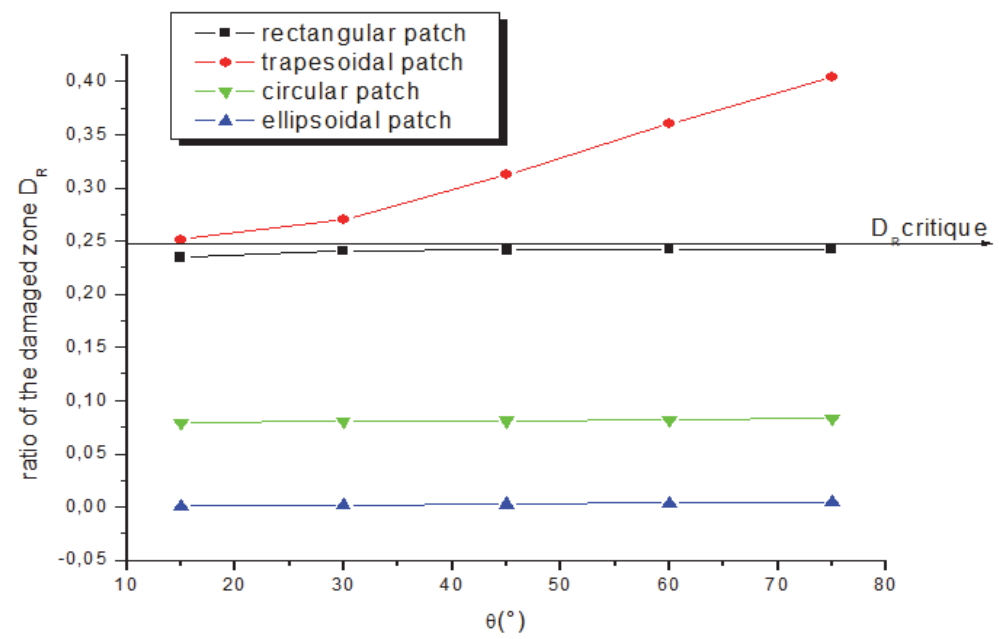

Figure 12: Ratio of the damaged zone according to the crack tilt for the different patch shapes.

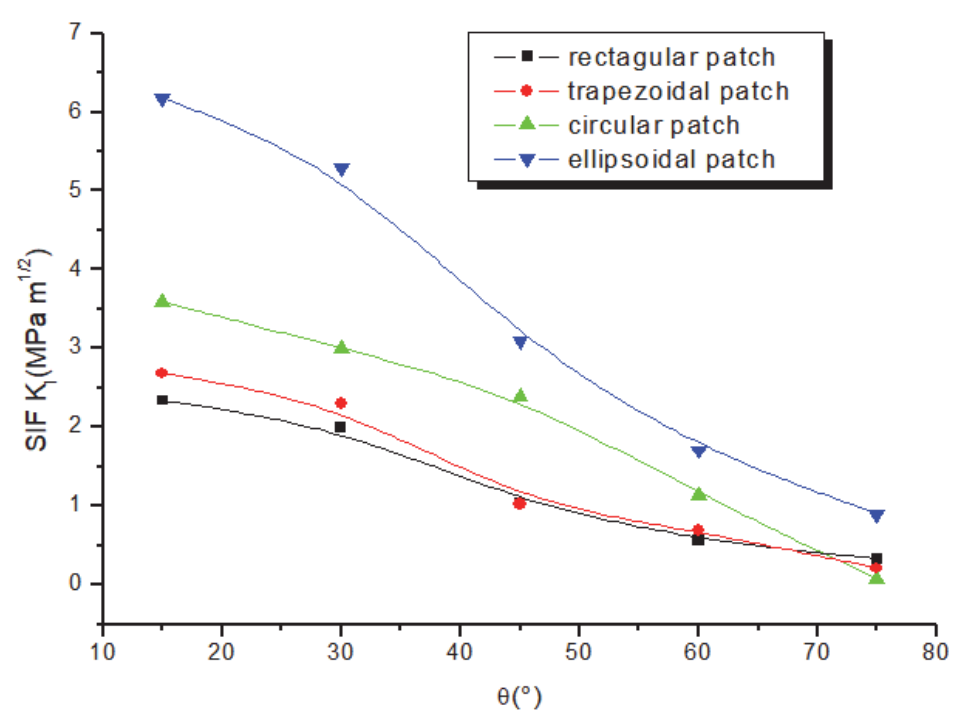

Figure 13: Variation of the (SIF) in mode I of the inclined crack for the different shape of patch $(\mathrm{a}=30 \mathrm{~mm})$

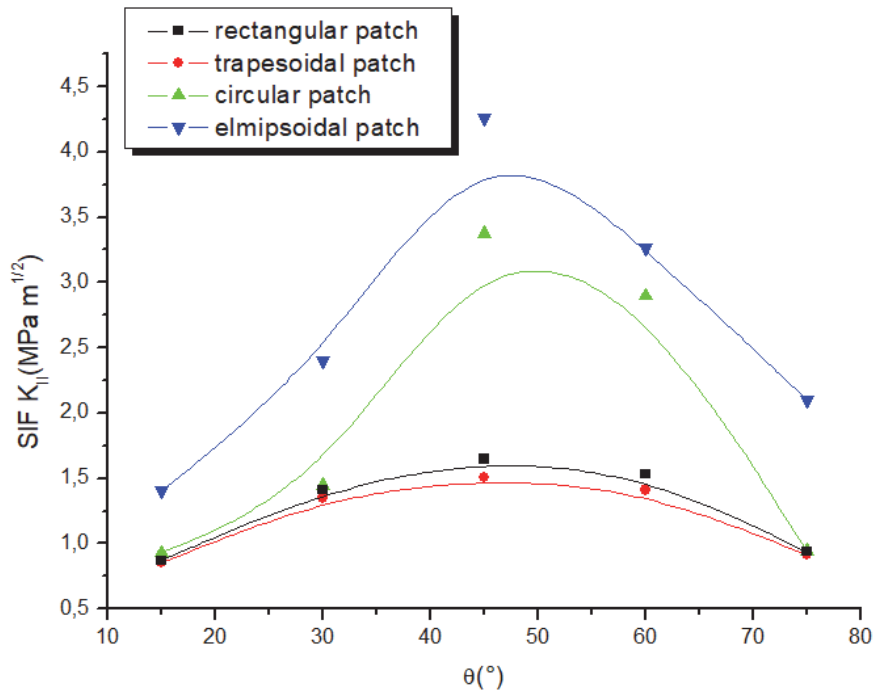

Figure 14: Variation of the (SIF) in mode II of the inclined crack for the different shape of patch $(\mathrm{a}=30 \mathrm{~mm})$. 
Fig. 13 shows that the $K_{I}$ value for different patch shapes decreases with increasing angle $\theta$. The reduction of the SIF values between the ellipsoid and circular shaped patch is evaluated at $85 \%$ and about $20 \%$ for the trapezoidal and rectangular shapes. When the value goes to the angle $\theta=75^{\circ}$ the value of SIF tends to zero. For angle $\theta=0{ }^{\circ}$ we have a pure mode I from which the opening of the crack is maximum with high SIF values. For angle $\theta=75^{\circ}$, the crack being at a position almost parallel to the loading the SIF values tend to zero. Concerning the mixed mode of SIF, according to Fig. 14 , this factor (characterizing the sliding of the crack) is zero when the crack is perpendicular to the direction of loading, which passes through a maximum then tends towards a minimum when the inclination the crack tends to the angle $\theta=75$ $\circ$. The value of $K_{I I}$ is maximum for the angle $\theta=45^{\circ}$ for all forms. Circular and ellipsoidal shapes give higher $K_{I I}$ values than rectangular and trapezoidal shapes.

\section{CONCLUSION}

his work involves evaluating the damaged area of the adhesive from the effect of crack tilt. The objective is to calculate the ratio of the damaged area and to determine the stress intensity factor, then compare the results for the different shapes of the patch (rectangular, trapezoidal, circular and ellipsoidal), with an inclined crack (mixed mode) the results obtained allow the following conclusions:

-The increase of the crack inclination leads to an increase of $\mathrm{D}_{\mathrm{R}}$ for all the different forms of patch used.

-The risk of detachment of the patch can be observed for the trapezoidal shape which is due to $\mathrm{D}_{\mathrm{R}}$ greater than the critical value for the different $\theta$.

- The $K_{I}$ value decreases with the increase of the angle and the $K_{I I}$ value is maximum for the angle $\theta=45^{\circ}$ for all the shapes of the patch.

\section{REFERENCES}

[1] Bachir Bouiadjra, B.B., Achour, T., Berrahou, M., Ouinas, D. and Feaugas, X. (2010). Numerical estimation of the mass gain between double symmetric and single bonded composite repairs in aircraft structures, Mater. Des., 31, pp. 3073-3077. DOI: 10.1016/j.matdes.2010.01.006.

[2] Baker, A. (1984). Repair of cracked or defective metallic aircraft components with advanced fiber composites-an overview of Australian work, J. Compos. Struct., 2, pp. 153-8. DOI: 10.1016/0263-8223(84)90025-4.

[3] Baker, A. (1995). Bonded composite repair of metallic aircraft components overview of Australian activities, AGARD-CP-550, pp. 1-14.

[4] Pfeifer, W.H. (1977). Graphite/aluminum technology development, Hybrid and select metal matrix composites: A state-of-the-art review, pp. $159-252$.

[5] Turnbull, A. (1992). Review of corrosion studies on aluminum metal matrix composites, British Corrosion Journal, 27, pp. 27-35. DOI: $10.1179 / 000705992798268864$.

[6] Jones, R. and Chiu W.K. (1999). Composite repairs to crack in thick metallic components, Compos. Struct., 44, pp. 17-29. DOI: 10.1016/S0263-8223(98)00108-1.

[7] Berrahou, M. and Bachir Bouiadjra B. (2016). Analysis of the adhesive damage for different patch shapes in bonded composite repair of corroded aluminum plate, Techno. press., 59, pp. 123-132.DOI: 10.12989/sem.2016.59.1.123.

[8] Berrahou, M., M, Salem., M., Mechab, B. and Bachir Bouiadjra B. (2017). Effect of the corrosion of plate with double cracks in bonded composite repair, Techno. press., 64, pp. 323-328.DOI: 10.12989/sem.2017.64.3.323.

[9] Vargel, C. (1999). Corrosion de l'aluminium, Corrosion Reviews, Paris, pp. 154-176.

[10] Bachir Bouiadjra, B., Fari, Bouanani., M, Albedah., A, Benyahia., F and Es-Saheb, M. (2011). Comparison between rectangular and trapezoidal bonded composite repairs in aircraft structures: a numerical analysis, Mater. Des., 32, pp. 3161-3166. DOI: 10.1016/j.matdes.2011.02.053.

[11] Salem, M., Bachir Bouiadjra, B.B., Mechab, B. and Kaddouri, K. (2015). Elastic-plastic analysis of the J integral for repaired cracks in plates, Adv .Mater.Res., 4, pp. 87-96. DOI: 10.12989/amr.2015.4.2.000.

[12] Mechab, B., Chama, M., Kaddouri, K. and Slimani, D. (2016). Probabilistic elastic-plastic analysis of repaired cracks with bonded composite patch, Steel. Compos. Struct. Int. J., 20, pp. 1173-1182. DOI:10.12989/scs.2016.20.6.1173.

[13] Serier, N., Mechab, B., M'hamdia, R. and Serier, B., (2016). A new formulation of the J integral of bonded composite repair in aircraft structures, Struct. Eng. Mech., 58, pp. 745-755. DOI: 10.12989/sem.2016.58.5.745. 
[14] Crocombe, A. and Richardson, G. (1995). A unified approach for predicting the strength of cracked and non-cracked adhesive joints, Int. J. Adhes., 49, pp. 211-44. DOI: 10.1080/00218469508014357.

[15] Sheppard, A., Kelly, D. and Tong, L. (1998). A damage zone model for the failure analysis of adhesively bonded joints, Int. J. Adhes., 18, pp. 385-400. DOI: 10.1016/S0143-7496(98)00024-4.

[16] Magalhães, A.G. and De Moura M.F.S.F., Gonçalves, JPM. (2005). Evaluation of stress concentration effects in single-lap bonded joints of laminate composite materials, Int. J. Adhes. 25, pp. 313-319. DOI: 10.1016/j.ijadhadh.2004.10.002.

[17] Chang-Su, B.,Young-Hwan, L., Jin-Ho, C. and Jin-Hwe, K. (2008). Strength prediction of adhesive joints using the modified damage zone theory, Compos. Struct., 86, pp. 96-100. DOI: 10.1016/j.compstruct.2008.03.016.

[18] Kemal Apalak, M., Gul Apalak, Z. and Gunes, R. (2004). Thermal and geometrically nonlinear stress analyses of an adhesively bonded composite, tee joint with double support, Thermoplast. Compos. Mater. 17, pp. 103-36. DOI: $10.1177 / 0892705704033337$.

[19] Fari Bouanani, M., Benyahia, F., Albedah, A., Aid, A., B. Bachir Bouiadjra, B.B., Belhouari, M. and Achour, T. (2013). Analysis of the adhesive failure in bonded composite repair of aircraft structures using modified damage zone theory, Mater. Des., 50, pp. 433-439. DOI: 10.1016/j.matdes.2013.03.017.

[20] Ramji, M., Srilakshmi, R. and Bhanu Prakash, M. (2013). Towards optimization of patch shape on the performance of bonded composite repair using FEM, Compos. B. Eng., 45, pp. 710-20. DOI: 10.1016/j.compositesb.2012.07.049.

[21] Benyahia, F., Fari Bouanani, M., Albedah, A., Bachir Bouiadjra, B. B. and Achour, T., (2014). Effect of water absorption on the adhesive damage in bonded composite repair of aircraft structures, Mater. Des., 57, pp. 435-441. DOI: 10.1016/j.matdes.2013.12.081.

[22] Benyahia, F., Albedah, A. and Bachir Bouiadjra, B.B., (2014). Analysis of the adhesive damage for different patch shapes in bonded composite repair of aircraft structures, Mater. Des., 54, pp. 18-24. DOI: 10.1016/j.matdes.2013.08.024.

[23] Abaqus, ABAQUS standard/user's manual, version 6.11. Hibbit Karlsson \& Sorensen, Inc., Pawtucket, RI, USA, (2007).

[24] Henshel, R. D. and Shaw, K. G., (1975). Crack tip finite elements are unnecessary, Int. J. Num. Meth. Eng., 9, pp. 495- 507. DOI: $10.1002 /$ nme.1620090302. 